Research Article

\title{
Electrodeposition of Oriented Cerium Oxide Films
}

\author{
Adele Qi Wang and Teresa D. Golden \\ Department of Chemistry, 1155 Union Circle No. 305070, University of North Texas, Denton, TX 76203, USA
}

Correspondence should be addressed to Teresa D. Golden; tgolden@unt.edu

Received 19 July 2013; Revised 12 September 2013; Accepted 13 September 2013

Academic Editor: Benjamín R. Scharifker

Copyright (C) 2013 A. Q. Wang and T. D. Golden. This is an open access article distributed under the Creative Commons Attribution License, which permits unrestricted use, distribution, and reproduction in any medium, provided the original work is properly cited.

Cerium oxide films of preferred orientation are electrodeposited under anodic conditions. A complexing ligand, acetate, was used to stabilize the cerium (III) ion in solution for deposition of the thin films. Fourier transform infrared spectroscopy showed that the ligand and metal tended to bind as a weakly bidentate complex. The crystallite size of the films was in the nanometer range as shown by Raman spectroscopy and was calculated from X-ray diffraction data. Crystallite sizes from 6 to $20 \mathrm{~nm}$ were obtained under the anodic deposition conditions. Sintering of the (111) oriented films showed an increase in the (111) orientation with temperatures up to $900^{\circ} \mathrm{C}$. Also, the crystallite size increased from $20 \mathrm{~nm}$ to $120 \mathrm{~nm}$ under sintering conditions. Addition of the deposited films to the substrate improved corrosion resistance for the substrate.

\section{Introduction}

The fabrication of cerium oxide films is of interest due to broad applications for these films [1-6]. Cerium oxide can function as a catalyst, structure barrier for insulator on silicon, buffer layer on superconductor materials, and an anticorrosion coating on metals [7-12]. The texture of these thin films can affect the mechanical, electronic, and corrosion properties.

Electrochemical deposition is an attractive method for the synthesis of thin films. It offers the advantages of low processing temperature, high purity of deposition, and controlled thickness of the film. Cathodic electrodeposition (i.e., base generation electrochemical methods) was first introduced for the plating of cerium oxide films [13-17]. However, producing $\mathrm{CeO}_{2}$ films with the base generation method is limited since the as-produced films tend to be powdery and loosely adherent.

It is possible to obtain thin films of cerium oxide by stabilizing $\mathrm{Ce}^{3+}$ in solution with a weakly bound ligand [1820]. With a high enough oxidation potential at the electrode surface, an equilibrium can be established where Ce(III)-L has a slow release of $\mathrm{Ce}^{3+}$ from the complex for available oxidation. This mechanism has been described previously in greater detail [19]. These films can be electrodeposited under potentiostatic control and produce polycrystalline films of random orientation [18-21]. XANE study on electrodeposited cerium-related thin films revealed that anodic deposition preferred the Ce(IV) compounds, while cathodic base generation method led to the formation of high percentage of $\mathrm{Ce}(\mathrm{III})$ species in the composition [22]

For corrosion protection, cerium oxide has been used as coatings on stainless steel. While stainless steel can give protection against corrosion in certain environments, there is a need for resistance in other environments. This can be especially true for such places as coal and heavy oil plants [23] or in marine environments [24]. Since nickel has been increasing in price over recent years, there is an interest in shifting from austenitic to ferritic steels where possible. One of the largest drawbacks to using ferritic stainless steels, such as type 430, is less resistance to corrosion. Pitting corrosion especially in chloride containing environments can be a problem for type 430 stainless steel [25].

In this work, $\mathrm{CeO}_{2}$ is deposited with a preferred crystalline orientation. This is accomplished by precisely controlling the deposition parameters. The resulting films are characterized by scanning electron microscopy, X-ray diffraction, Fourier transform infrared spectroscopy, and Raman spectroscopy. The sintering ability and corrosion protection of the films are also studied. 


\section{Experimental}

An EG\&G Princeton Applied Research (PAR) Model 273A potentiostat/galvanostat was used to electrochemically deposit $\mathrm{CeO}_{2}$ films. The electrochemical cell was kept at constant temperature with a Fisher Scientific Model 1016D circulator. The deposition was conducted in an undivided cell and regular three-electrode configuration. The working electrode was prepared by mounting stainless steel (type 430, nominal composition $0.12 \%$ C, $1 \% \mathrm{Mn}, 1 \% \mathrm{Si}, 0.04 \% \mathrm{P}$, $0.03 \% \mathrm{~S}, 0.75 \% \mathrm{Ni}, 17 \% \mathrm{Cr}, \mathrm{Fe}$ ) or platinum in epoxy and then polished, rinsed, and ultrasonicated to a mirror finish. Platinum wire or mesh was used as the counter electrode and a saturated calomel electrode (SCE) as the reference. The electrolyte consisted of $0.1 \mathrm{M} \mathrm{Ce}\left(\mathrm{NO}_{3}\right)_{3} \cdot 6 \mathrm{H}_{2} \mathrm{O}(99.5 \%$ pure, Alfa AESAR) and sodium acetate (Fisher) as a ligand. $\mathrm{Ce}\left(\mathrm{NO}_{3}\right)_{3}$ and ligand concentrations were $0.1 \mathrm{M}$ throughout the study. All the solutions were prepared using deionized water. Solution $\mathrm{pH}$ was adjusted with $\mathrm{NaOH}$ and monitored with a Corning $\mathrm{pH}$ meter and Pasco Scientific $\mathrm{pH}$ electrode throughout the deposition experiments. Each deposition was completed in 24-48 hours.

The deposited film together with the substrate was sintered in air. A temperature ramping procedure was used starting at $260^{\circ} \mathrm{C}$ with a ramping rate of $1^{\circ} \mathrm{C} / \mathrm{min}$ to the desired temperature value, keeping the value for one hour, and finally decreasing the temperature at a ramping rate of $1^{\circ} \mathrm{C} / \mathrm{min}$ to $260^{\circ} \mathrm{C}$.

The structure and phase composition of the electrochemical deposited films were identified by X-ray diffraction (XRD) with a Siemens D500 diffractometer using $\mathrm{Cu} \mathrm{K} \alpha$ radiation $(\lambda=0.15405 \mathrm{~nm})$. The tube source was operated at $40 \mathrm{kV}$ and $30 \mathrm{~mA}$.

The surface morphology of the films was characterized by a scanning electron microscope (SEM), JOEL JSM-T300 with an accelerating voltage of $5-25 \mathrm{kV}$.

Raman spectra were obtained using a Yvon Dilor XY800 Raman microprobe equipped with a nitrogen-cooled multichannel (CCD) detector, with an excitation wavelength of $514.54 \mathrm{~nm}$ laser radiation at $10 \mathrm{~mW}$ of power to prevent local heating of the sample. All the spectra were recorded between 200 and $4000 \mathrm{~cm}^{-1}$ with $3 \mathrm{~cm}^{-1}$ spectra resolution, $719 \mathrm{~mm}$ focal length, 600 lines/mm gratings, and 10x objective focused to $10 \mu \mathrm{m}$ spot size. At least three spectra were randomly collected from different areas of the films and plotted.

Infrared spectra were obtained using a Perkin-Elmer 1760X FTIR spectrophotometer. For each sample, 40 scans were collected in the range of $4000-400 \mathrm{~cm}^{-1}$ with a resolution of $4 \mathrm{~cm}^{-1}$.

Linear polarization and Tafel experiment were done with EG\&G 273A potentiostat using EG\&G 352 softcorr III.

\section{Results and Discussion}

$\mathrm{Ce}^{3+}$ has the electronic structure of $4 \mathrm{f}^{1} 5 \mathrm{~d}^{0} 6 \mathrm{~s}^{0}$, and as a trivalent member of lanthanide series, the most stable complexes are those with chelating oxygen ligands [26]. Previously,

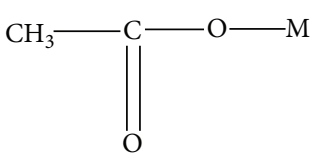

(a)

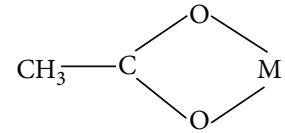

(b)

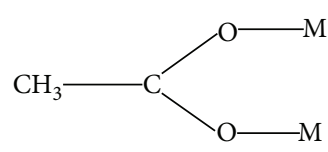

(c)

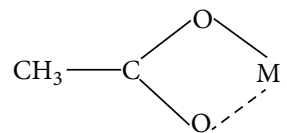

$\left(b^{\prime}\right)$

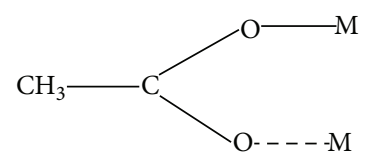

$\left(c^{\prime}\right)$
FIGURE 1: Coordination modes of acetate with metal, $\mathrm{M}=$ metal; (a) unidentate; (b) bidentate, symmetrical; (b') bidentate, unsymmetrical; (c) bridging, symmetrical; (c') bridging, unsymmetrical.

acetate and lactate have been shown as ligands to result in film formation of $\mathrm{CeO}_{2}$ on substrates [18-21]. Kulp et al. studied acetate ions as stabilizing agents for cerium (III) to determine the predominant species in the deposition solution. At a $\mathrm{pH}$ of 6.1 , the main species was $\mathrm{CeOAc}^{2+}$, and the cerium (III)-ligand complex proved significant for the anodic deposition of $\mathrm{CeO}_{2}$ films [21]. As a complexing agent, the acetate ion may be bound with the metal as a unidentate, bidentate, or bridging type with the later two classified as symmetrical or unsymmetrical (Figure 1) [2729]. Unidentate oxygen ligands are less stable than the others and are prone to dissociation.

FTIR can be useful to probe the coordination between acetate and cerium (III) species [28, 30-32]. Symmetrical and antisymmetric C-O stretching modes are at $\sim 1415 \pm 20$ and $\sim 1570 \pm 20 \mathrm{~cm}^{-1}$, respectively. These two characteristic IR bands will alter in position and shape with different coordination modes. If acetate is a unidentate, one of the oxygen is used in bonding with the metal, leaving a double-bond $(\mathrm{C}=\mathrm{O})$ giving a $1590-1650 \mathrm{~cm}^{-1}$ peak for the antisymmetric stretch mode. The large increase in the antisymmetric band and the corresponding decrease in the symmetrical band increase the frequency difference between these two emissions. With acetate as a bidentate ligand, the two $\mathrm{C}-\mathrm{O}$ bonds retain equivalent stretching, giving no enhancement for the two bands [28]. Coupling between different acetate groups leads to multiple bands in the range of $1400-1550 \mathrm{~cm}^{-1}$, if more than one acetate bonds to a metal ion [32]. Bridging can also be regarded as an intermediate mode between uni- and bidentate coordinations [32].

Solutions of cerium (III) nitrate-acetate with a molar ratio of cerium (III) to acetate in the range of $1: 1$ to $1: 9$ were run using FTIR. The results are shown in Figures 2 and 3. The acetate ligand alone in solution exists as ions and the 


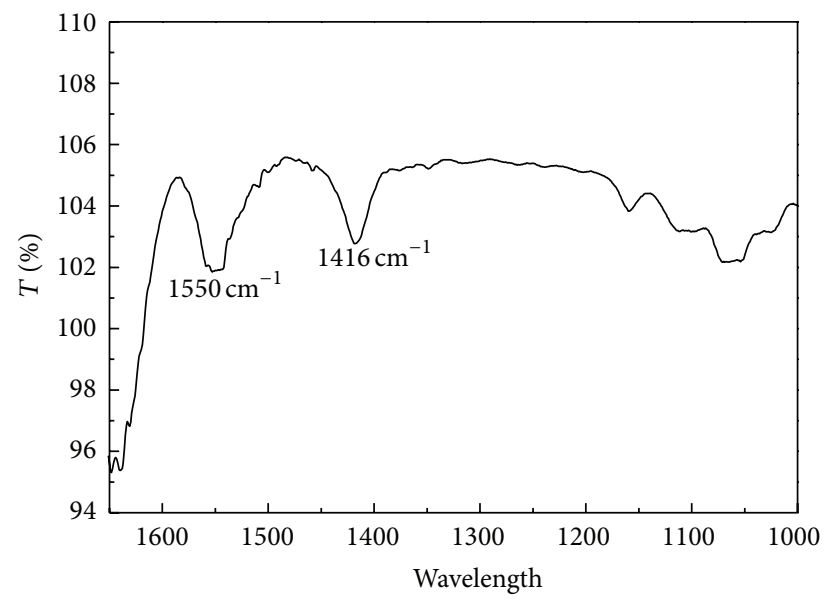

FIGURE 2: FTIR spectra for acetate ion in solution.

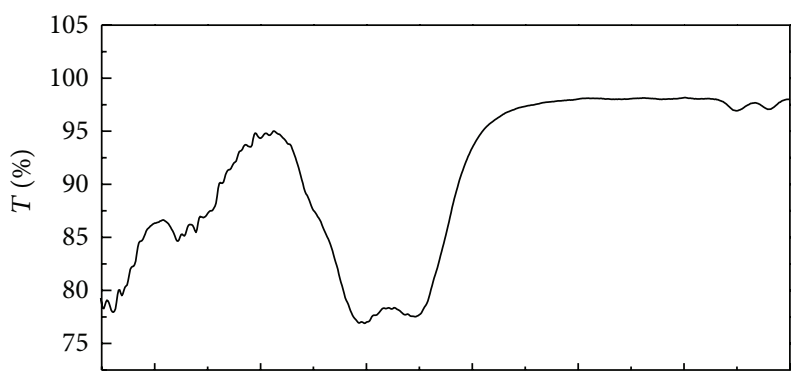

(a)

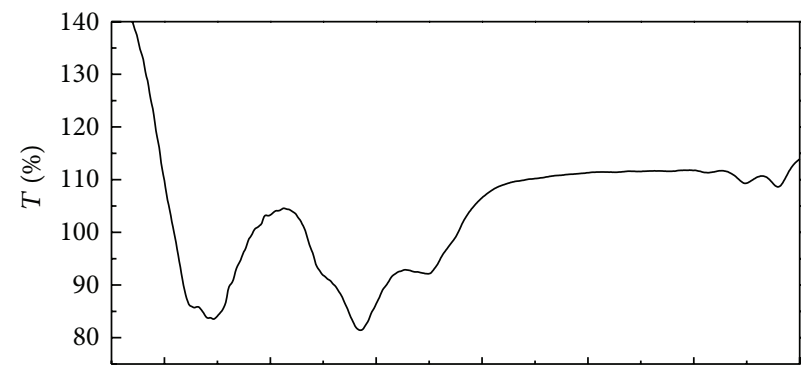

(b)

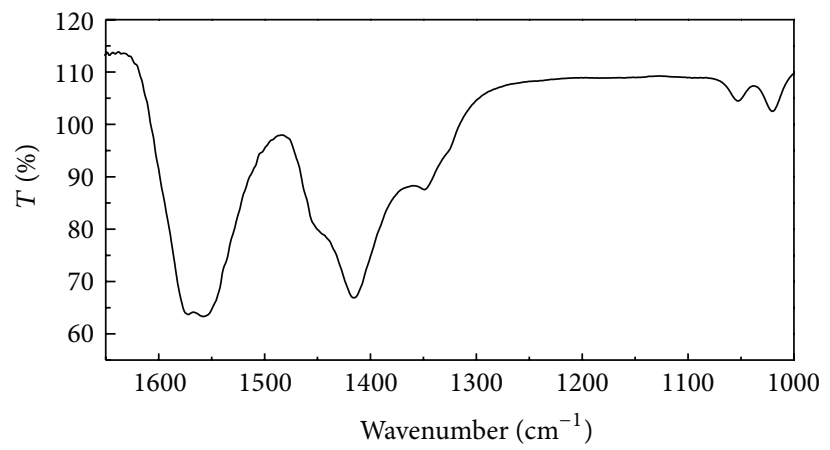

(c)

FIGURE 3: FTIR spectra for cerium (III)-acetate complex in the range of $1000-1650 \mathrm{~cm}^{-1}$ and molar ratio of cerium and acetate (a) $1: 1$; (b) $1: 6$; (c) $1: 10$.

two $\mathrm{C}-\mathrm{O}$ stretching bands are equivalent indicating $\mathrm{C}=\mathrm{O}$ and $\mathrm{C}^{-} \mathrm{O}^{-}$, as would be expected for the free ion (Figure 2). Figure 3 shows the IR spectrum changes with the molar ratio between cerium (III) and acetate increasing from $1: 1$ to $1: 10$. At lower concentrations of acetate, the $\sim 1415 \mathrm{~cm}^{-1}$ bands (symmetrical) are enhanced and split into two bands, at 1404 and $1352 \mathrm{~cm}^{-1}$, respectively, with weak peaks around 1560 and $1577 \mathrm{~cm}^{-1}$ (Figure 3). The pair of 1404 and $1560 \mathrm{~cm}^{-1}$, which results in the difference of $\sim 156 \mathrm{~cm}^{-1}$ (Table 1), shows an enhanced bidentate complex [28]. The higher frequency of $1577 \mathrm{~cm}^{-1}$ is very weak so the predominant binding is with $\mathrm{C}_{-} \mathrm{O}^{-}$. The stronger intensities of the lower frequencies can be attributed to the complex having symmetrical properties, pointing to a symmetrical bidentate complex. These 1:1 metal:acetate results coincide with the luminescence and NMR results reported by Azenha et al. which show that the dominant mode of complexation involved a weak, predominately bidentate binding of the metal ion, suggesting 
TABLE 1: IR assignment for Ce(III)-acetate complex and calculation of frequency difference (peak position in $\mathrm{cm}^{-1}$ ) according to Figure 3.

\begin{tabular}{|c|c|c|c|c|c|c|}
\hline $\begin{array}{l}\text { Emission } \\
\text { Emission type }\end{array}$ & $\begin{array}{c}\text { a } \\
\text { Sym }\end{array}$ & $\begin{array}{c}\mathrm{b} \\
\text { Sym } \\
\end{array}$ & $\begin{array}{c}c \\
\text { An-sym }\end{array}$ & $\begin{array}{c}\mathrm{d} \\
\text { An-sym }\end{array}$ & Diffl & Diff2 \\
\hline \multicolumn{7}{|l|}{ Ce: Acetate } \\
\hline $0: 1$ & & 1417.6 & 1552 & & 134.4 & \\
\hline $1: 1$ & 1352.8 & 1404 & 1560.0 & 1581.2 & 156 & 228.4 \\
\hline $1: 2$ & 1350.9 & 1411.2 & 1556.4 & 1577.6 & 145.2 & 226.7 \\
\hline $1: 3$ & 1350.9 & 1414.7 & 1554.6 & 1577.6 & 139.9 & 226.7 \\
\hline $1: 4$ & 1353.9 & 1414.7 & 1556.1 & 1576.5 & 141.4 & 222.6 \\
\hline $1: 5$ & 1350.9 & 1416.5 & 1554.6 & 1577.6 & 138.1 & 226.7 \\
\hline $1: 6$ & 1347.8 & 1416.5 & 1554.2 & 1576.5 & 137.7 & 228.7 \\
\hline $1: 7$ & 1351.6 & 1416.5 & 1556.1 & 1576.5 & 139.6 & 224.9 \\
\hline $1: 8$ & 1349.7 & 1414.7 & 1556.1 & 1576.5 & 141.4 & 226.8 \\
\hline $1: 9$ & 1347.8 & 1414.7 & 1556.1 & 1576.5 & 141.4 & 228.7 \\
\hline $1: 10$ & 1350.7 & 1415.1 & 1556 & 1576.1 & 140.9 & 225.4 \\
\hline
\end{tabular}

a $\left[\mathrm{Ce}\left(\mathrm{H}_{2} \mathrm{O}\right)_{x}\left(\mathrm{O}_{2} \mathrm{CCH}_{3}\right)\right]^{2+}$ species (where $x=6$ or 7$)$ [33]. Kulp et al., also calculated this species as the predominant form in the electrodeposition solution [21].

With increasing amount of acetate, the $1350 \mathrm{~cm}^{-1}$ band decreases, but the splitting is still sustained (Figure 3), indicating, the coordination is two modes but with the bridging gradually dominating. Also the higher frequency band, $\sim 1560 \mathrm{~cm}^{-1}$ gives a strong signal. FTIR results showed that for molar ratios of $1: 2$ to $1: 7$, similar IR spectra were obtained suggesting the saturation of coordination with increasing amounts of acetate. When the molar ratio is increased to as high as $8-10$, the 1570 and $1550 \mathrm{~cm}^{-1}$ bands merge and give higher intensities. Considering the saturation of metal coordination, the extra free ions of acetate contribute more to the IR spectra. The coordination number of the Ce(III)acetate complex is estimated at 6-7 with weak bidentate coordination for the 1:1 complex and bridging at higher concentrations. More accurate determination of complex coordination number can be acquired by combining IR and solid-state NMR with single-crystal X-ray diffraction. Since the $1: 1$ ratio provided the least complicated complexation, this molar ratio was used in the deposition of the oriented films.

Several parameters were explored to optimize the deposition of the $\mathrm{CeO}_{2}$ films with preferred orientation. The linear sweep voltammogram is shown in Figure 4 for the plating solution used for the cerium oxide film deposition. A small oxidation peak can be seen around a potential of $\sim 0.95 \mathrm{~V}$ that is attributed to the conversion of $\mathrm{Ce}$ (III) to $\mathrm{Ce}(\mathrm{IV})$ species [19]. While potentiostatic and galvanostatic modes were both shown to give $\mathrm{CeO}_{2}$ films, galvanostatic mode resulted in preferred orientation of the films when higher temperatures were used. A range of current densities were studied at $25^{\circ} \mathrm{C}$ for anodic current densities between -0.06 and $-0.90 \mathrm{~mA} / \mathrm{cm}^{2}$. The deposited films exhibited a random pattern, with increasing current, and the intensity of the (111) reflection decreases. The lower currents (i.e., $-0.06 \mathrm{~mA} / \mathrm{cm}^{2}$ ) are more conducive to the formation of preferred orientation. The effect of deposition temperature was then investigated at these lower current densities.

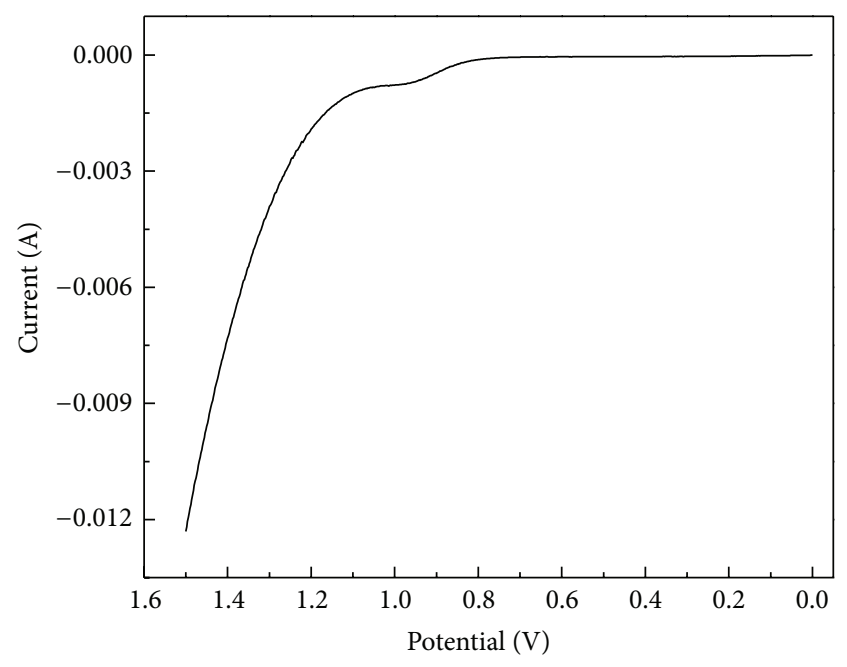

FIGURE 4: Linear sweep voltammetry of cerium-acetate complex, $\mathrm{pH}$ $=7.5, T=25^{\circ} \mathrm{C}$, and $\nu=50 \mathrm{mV} / \mathrm{sec}$.

Increasing the temperature increases the steady state current density for the cerium-acetate system. The X-ray diffraction patterns of the deposited films are shown for higher temperatures of $70^{\circ}$ and $80^{\circ} \mathrm{C}$ (Figure 5). With increasing temperature, for the galvanostatic deposition, the $\mathrm{CeO}_{2}$ (111) reflection increases in intensity producing films with a preferred (111) orientation, while the potentiostatic deposition only produces random oriented films. The intensity ratios $\left(I / I_{\mathrm{o}}\right)$ for the $\mathrm{CeO}_{2}$ patterns in Figure 5 are shown in Table 2. While the (111) intensity of the $\mathrm{CeO}_{2}$ increases, the substrate peak remains about the same intensity, indicating that the film thickness is approximately the same at all temperatures. The film thicknesses for all depositions tend to be thin since $\mathrm{CeO}_{2}$ is not very conducting.

The potential monitored during galvanostatic deposition for a current density of $-0.06 \mathrm{~mA} / \mathrm{cm}^{2}$ is in the range of $0.7-1.0 \mathrm{~V}$ versus SCE. Progressing through the deposition, the potential increases to $0.9-1.1 \mathrm{~V}$. However, when these corresponding potentials are applied in the potentiostatic 


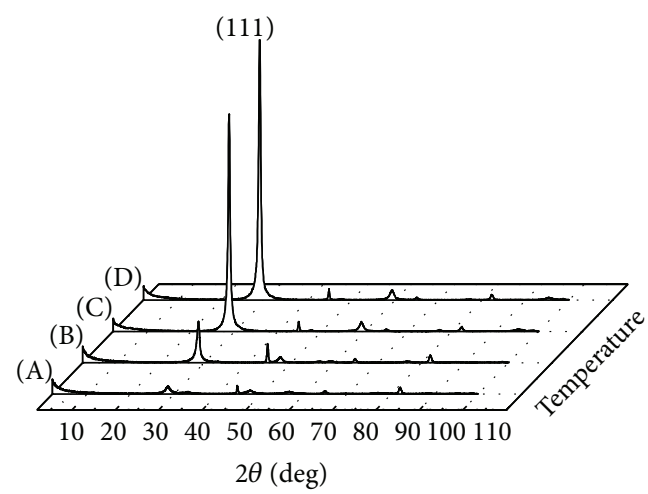

(a)

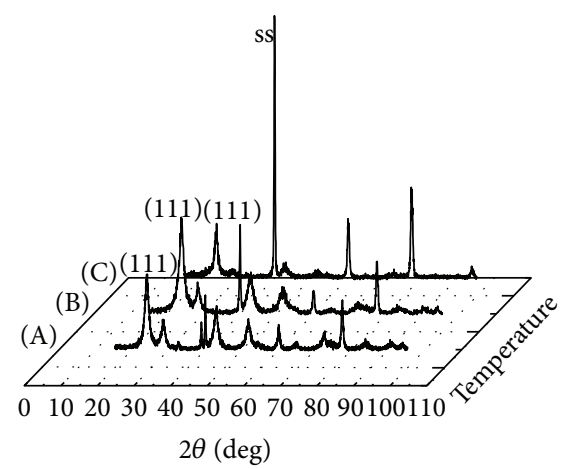

(b)

FIGURE 5: X-ray diffraction patterns of cerium oxide films deposited from a solution of $0.1 \mathrm{M} \mathrm{Ce}\left(\mathrm{NO}_{3}\right)_{3}$ and $0.1 \mathrm{M}$ acetic acid pH $=7.5, y$ axis X-ray intensity in cps. (a) Galvanostatic mode: deposition current density of $-0.06 \mathrm{~mA} / \mathrm{cm}^{2}$ at (A) 25 , (B) 50 , (C) 70 , and (D) $80^{\circ} \mathrm{C}$. (b) Potentiostatic mode: deposition potential of $1.10 \mathrm{~V}$ at (A) 25 , (B) 50 , and (C) $70^{\circ} \mathrm{C}$.

TABLE 2: The preferred orientation of $\mathrm{CeO}_{2}$ at various temperatures compared to the random powder pattern for $\mathrm{CeO}_{2}$ ( $\mathrm{PDF}_{\text {number } 81-0792)}$ (data from Figure 5).

\begin{tabular}{lccccccc}
\hline $2 \theta\left(^{\circ}\right)$ & hkl & PDF number 81-0792 & $25^{\circ} \mathrm{C}$ & $40^{\circ} \mathrm{C}$ & $50^{\circ} \mathrm{C}$ & $60^{\circ} \mathrm{C}$ & $70^{\circ} \mathrm{C}$ \\
\hline 28.54 & 111 & 100 & 100 & 100 & 100 & 100 & 100 \\
33.03 & 200 & 29 & 29 & - & - & - & - \\
47.51 & 220 & 46 & 47 & 12 & 14 & 3 & - \\
56.34 & 311 & 36 & 33 & 2 & 2 & - & - \\
59.36 & 400 & 6 & 7 & 4 & 3 & 3 & 3 \\
\hline
\end{tabular}

deposition, a random structure is obtained, not preferred oriented films.

Raman spectroscopy is an effective tool to investigate the structure of cerium oxide and crystalline size of the $\mathrm{CeO}_{2}$ [34-37]. Crystallite size is a significant parameter for the properties and application of the cerium oxide film. Smaller particle sizes and minimum film thickness of cerium oxide films lead to improvements for corrosion protection. Other researchers have demonstrated this for $\mathrm{CeO}_{2}$ films deposited by sol-gel and reactive sputtering methods [38, 39]. In Wang's report, when the crystallite is larger than $20 \mathrm{~nm}$, there will be one major shift for the $463 \mathrm{~cm}^{-1}$ peak in Raman; however, for crystallite sizes smaller than $10 \mathrm{~nm}$, two more shifts at $270,315 \mathrm{~cm}^{-1}$ appear and the intensities increase with decreasing crystal sizes [34]. The Raman spectra of the anodically deposited $\mathrm{CeO}_{2}$ are shown in Figure 6 for galvanostatic deposited $\mathrm{CeO}_{2}$ films with an applied current density of $-0.06 \mathrm{~mA} / \mathrm{cm}^{2}$.

The reproducible spectra in each Raman spectra figure demonstrate the homogeneities of the deposited $\mathrm{CeO}_{2}$ film samples. The peak observed at $\sim 450 \mathrm{~cm}^{-1}$ is about $14 \mathrm{~cm}^{-1}$ lower relative to the reported peak $\left(464 \mathrm{~cm}^{-1}\right)$ for microsized $\mathrm{CeO}_{2}$, indicating that the crystallites are in the nanosize range. The lattice calculations, from the XRD patterns, support this observation for Raman.
For XRD patterns which exhibit preferred orientation, the following Scherrer equation is used to estimate the crystallite size [40];

$$
\beta=\frac{k \lambda}{L \cos \theta}
$$

where $\lambda$ is the wavelength of the X-rays, $\theta$ is the diffraction angle, $L$ is the crystallite size, $k$ is a constant dependent on the crystal shape, and $\beta$ is the corrected FWHM of the given peak. From the (111) reflection of the $\mathrm{CeO}_{2}$ films, the crystallite sizes for the preferred oriented films ranged from $6 \mathrm{~nm}$ for films deposited at $25^{\circ} \mathrm{C}$ and increased to $\sim 20 \mathrm{~nm}$ at higher deposition temperatures of $70^{\circ}-80^{\circ} \mathrm{C}$ (Figure 7).

Type 430 is used extensively in SOFC interconnects and is exposed to high temperatures [41]. However, type 430 can become sensitized with continuous annealing at higher temperatures of $900^{\circ} \mathrm{C}$ or above [42]. The (111) preferred oriented $\mathrm{CeO}_{2}$ deposited films were sintered at various temperatures for short time periods $(1 \mathrm{hr})$. The $\mathrm{CeO}_{2}$ (111) reflection in XRD becomes shaper and more intense as the sintering temperature increases up to $900^{\circ} \mathrm{C}$ (Figure 8). As the temperature is raised to $1100^{\circ} \mathrm{C}$ at a constant rate for the thin electrodeposited $\mathrm{CeO}_{2}$ film, the XRD pattern shows a change in both composition and orientation. The $\mathrm{CeO}_{2}$ reverts to a random arrangement with 100 -fold lower 


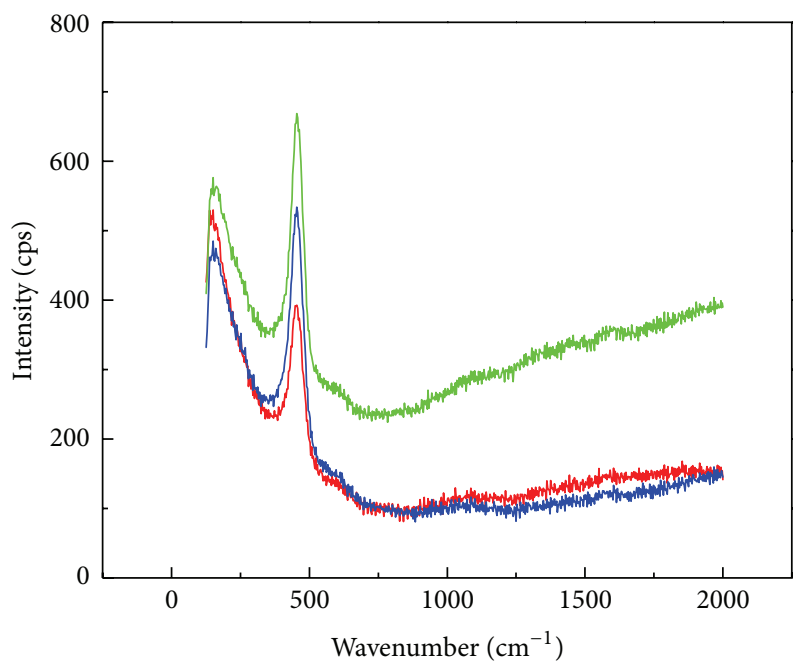

Figure 6: Raman spectra of $\mathrm{CeO}_{2}$ anodically electrodeposited on stainless steel by galvanostatic mode: $j=-0.06 \mathrm{~mA} / \mathrm{cm}^{2}, T=70^{\circ} \mathrm{C}$.

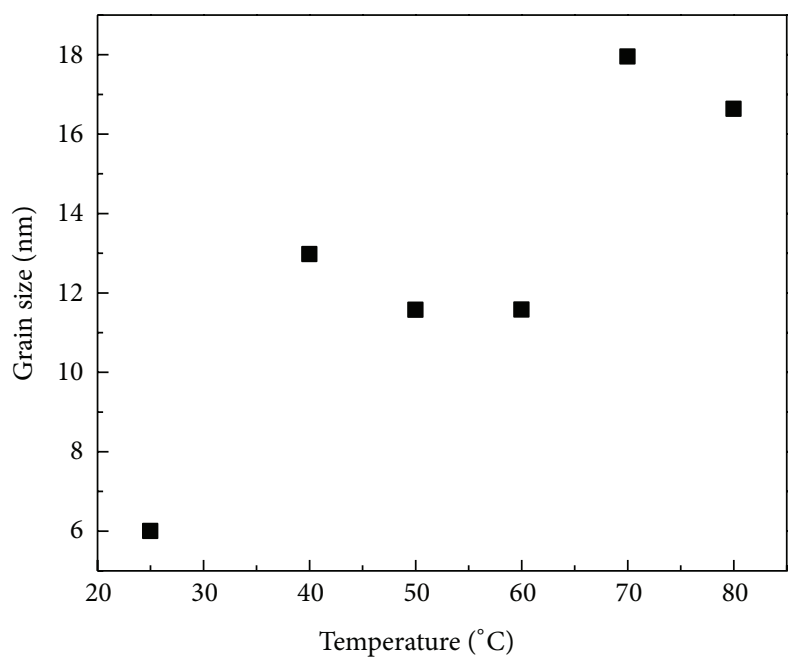

Figure 7: Grain size versus deposition temperature for galvanostatic deposition of $\mathrm{CeO}_{2}$ on stainless steel with $j=-0.06 \mathrm{~mA} / \mathrm{cm}^{2}$.

intensity. Accompanied with this is the evolution of strong substrate peaks indicating higher concentration of substrate components on the surface. Above $900^{\circ} \mathrm{C}$, oxidation of the substrate occurs during thermal treatment and migration of substrate ions to the surface. Sintering in an inert atmosphere may improve the temperature range at the higher limits. Crystallite size also changes with sintering temperature for the preferred oriented $\mathrm{CeO}_{2}$ films (Figure 9). The estimated crystallite size increases from $\sim 10 \mathrm{~nm}$ for the unsintered sample to $\sim 120 \mathrm{~nm}$ at $900^{\circ} \mathrm{C}$. A crystallite size minimum is obtained at a sintering temperature of $300^{\circ} \mathrm{C}$. It is reasonable to attribute this to the drying and dehydration of green films [43].

The microstructure features of the preferred oriented $\mathrm{CeO}_{2}$ films with sintering are shown in Figure 10. The unsintered $\mathrm{CeO}_{2}$ film exhibits a very smooth surface with cracking and this is probably due to a large mismatch between the substrate and film or drying process $[16,43]$. This type of cracking of $\mathrm{CeO}_{2}$ has also been observed for other wet chemical methods of deposition such as electrophoresis [14]. The cracking of the film is retained during sintering and shrinkage of the sample, and the cracking extends its width (Figures 10(b) and 10(c)), as the sintering temperature reaches 500 and $900^{\circ} \mathrm{C}[44]$. For the $1100^{\circ} \mathrm{C}$ sintered sample, corrosion is seen to progress on the $\mathrm{CeO}_{2}$ surface, with the appearance of bulk corrosion products $\left(\mathrm{Fe}_{2} \mathrm{O}_{3}\right.$, etc. $)$ discerned in the SEM.

Linear polarization and Tafel plots were applied to test the corrosion protection effect of the as deposited cerium oxide oriented films. The electrochemical corrosion parameters are summarized in Table 3. Calculated from the Tafel plots (Figure 11), the corrosion current decreases from $\sim 7.94 \times 10^{-9}$ for the substrate to $7.59 \times 10^{-10} \mathrm{~A} \cdot \mathrm{cm}^{-2}$ for the $\mathrm{CeO}_{2}$ film coated substrate in a $0.1 \mathrm{M} \mathrm{NaCl}$ solution. Correspondingly, 


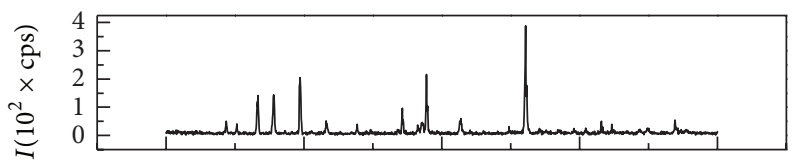

(e)

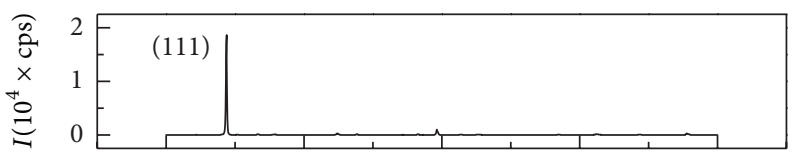

(d)

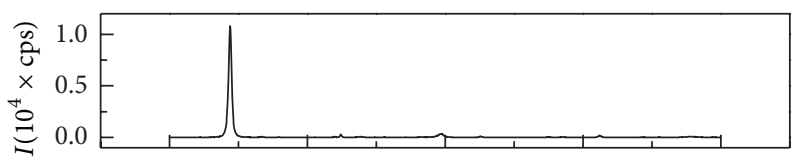

(c)

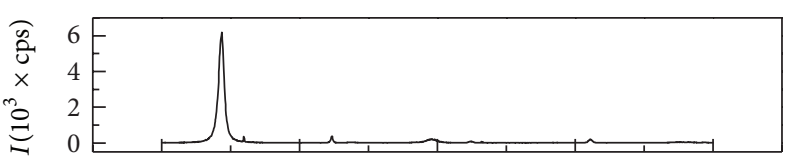

(b)

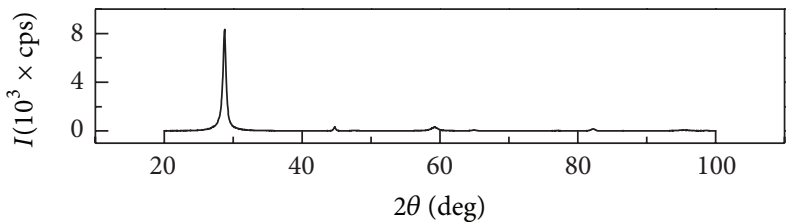

(a)

FIGURE 8: The XRD patterns for cerium oxide films electrodeposited in galvanostatic mode: $j=-0.06 \mathrm{~mA} / \mathrm{cm}^{2}, T=80^{\circ} \mathrm{C}$. (a) unsintered and sintered at temperatures of (b) $300^{\circ} \mathrm{C}$, (c) $500^{\circ} \mathrm{C}$, (d) $900^{\circ} \mathrm{C}$, and (e) $1100^{\circ} \mathrm{C}$.

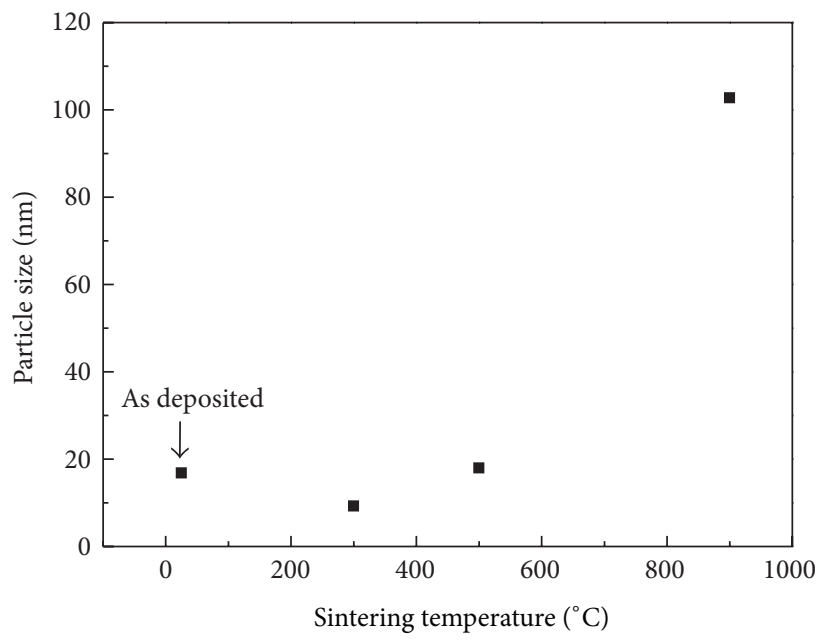

Figure 9: Crystallite size versus sintering temperature calculated from X-ray diffraction data of electrodeposited $\mathrm{CeO}_{2}$ films at $70^{\circ} \mathrm{C}$ with applied current density of $-0.06 \mathrm{~mA} / \mathrm{cm}^{2}$. 


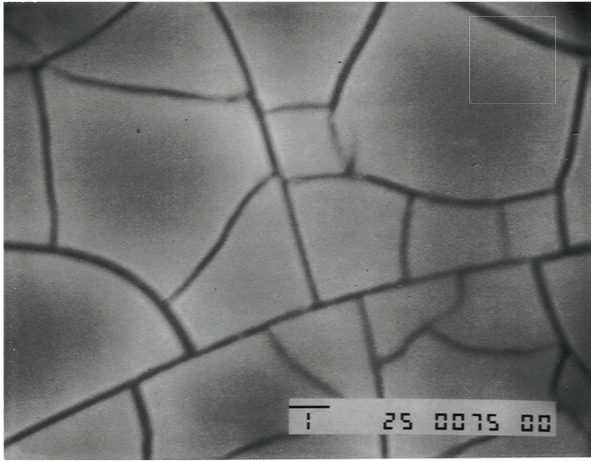

(a)

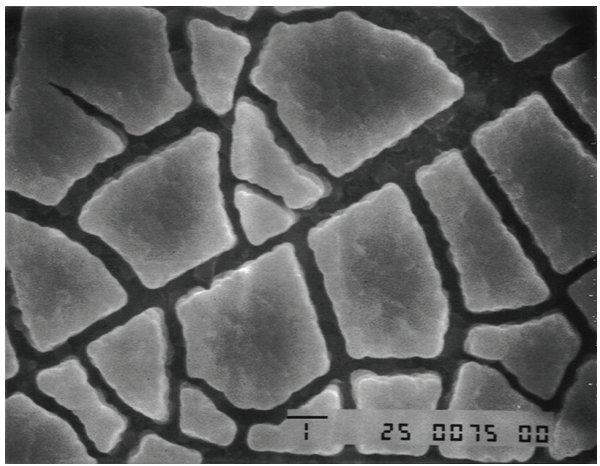

(c)

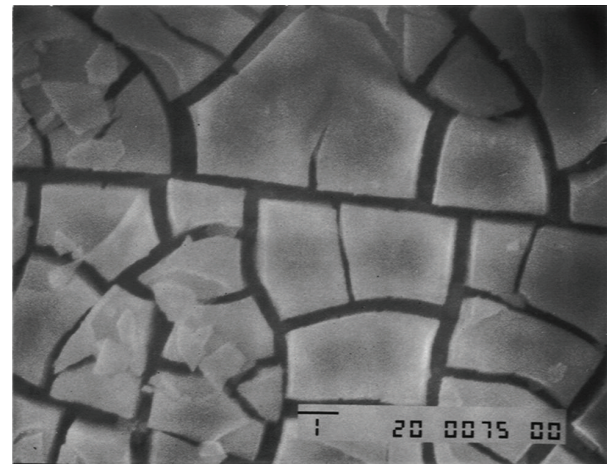

(b)

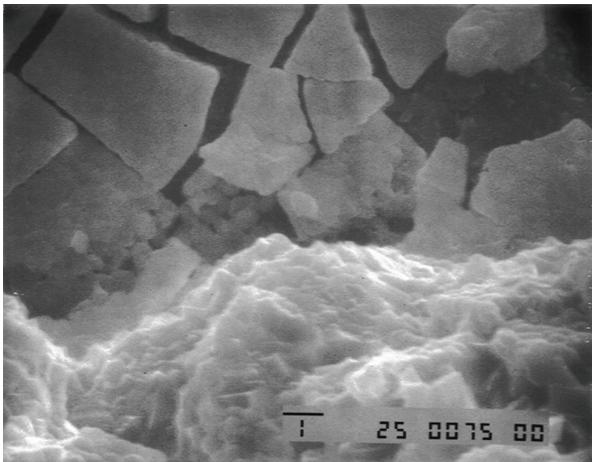

(d)

Figure 10: SEM morphologies for $\mathrm{CeO}_{2}$ deposited with galvanostatic mode at $80^{\circ} \mathrm{C}, j=-0.06 \mathrm{~mA} / \mathrm{cm}^{2}$; (a) unsintered: $\mathrm{x} 7500$; (b) sintered $500^{\circ} \mathrm{C}$ : $\mathrm{x} 7500$; (c) sintered at $900^{\circ} \mathrm{C}: \mathrm{x} 7500$; (d) sintered at $1100^{\circ} \mathrm{C}: \mathrm{x} 7500$.

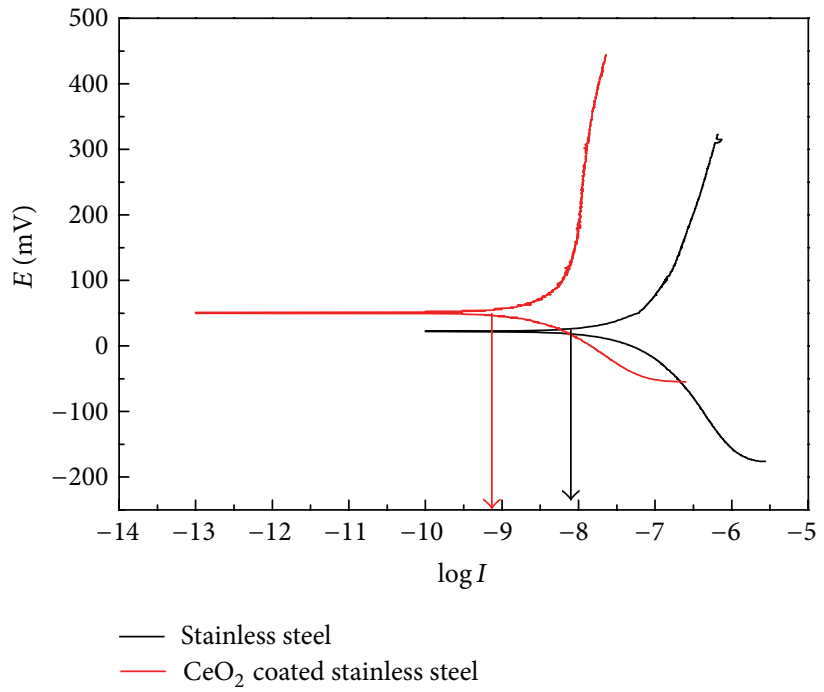

FIgURE 11: Tafel plots in $0.1 \mathrm{M} \mathrm{NaCl}$ solution.

the $R_{p}$ decreases from $2.63 \times 10^{6}$ for the substrate to 6.69 $\times 10^{7} \Omega \cdot \mathrm{cm}^{2}$ for the $\mathrm{CeO}_{2}$ film coated stainless steel. The $\mathrm{CeO}_{2}$ coated substrate exhibits a corrosion positive of the bare stainless steel, indicating an anodic corrosion inhibition mechanism involved for $\mathrm{CeO}_{2}$ coatings. A compact and intact $\mathrm{CeO}_{2}$ film on the surface impedes the ejection of metal ions into the electrolyte, thereby inhibiting corrosion reactions. Generally the immersion experiment suggested cerium oxide/hydroxide as a cathodic inhibitor [10]. However, Crossland and coworkers investigated the formation of anodized cerium oxide/hydroxide film out of $\mathrm{Al} / \mathrm{Ce}$ alloys and substantiated that this cerium-rich layer provides anodic 
TABle 3: Parameters of $E_{\text {corr }}, i_{\text {corr }}$, and $R_{p}$ of $\mathrm{CeO}_{2}$ film and stainless steel.

\begin{tabular}{lccc}
\hline Material & $E_{\text {corr }}(\mathrm{mV})$ & $i_{\text {corr }}\left(\mathrm{A} \cdot \mathrm{cm}^{-2}\right)$ & $R_{p}\left(\Omega \cdot \mathrm{cm}^{2}\right)$ \\
\hline $\mathrm{CeO}_{2}$ film & 50.8 & $7.5 \times 10^{-10}$ & $6.69 \times 10^{7}$ \\
Stainless steel & 20.9 & $7.94 \times 10^{-9}$ & $2.63 \times 10^{6}$ \\
\hline
\end{tabular}

inhibition to aluminum corrosion [11], which agrees with this study.

\section{Conclusion}

Cerium oxide (111) oriented thin films were successfully grown on stainless steel substrate with an anodic electrodeposition technique. A solution of cerium (III) and a weak organic ligand (acetate) at $\mathrm{pH}=7.5$ were used for the deposition. Preliminary investigation of the coordination between $\mathrm{Ce}(\mathrm{III})$ and the acetate ligand points to a bidentate complex for the 1:1 molar metal: acetate solutions. Preferred orientation of $\mathrm{CeO}_{2}$ films was obtained by tailoring the deposition conditions, suggesting that the optimized deposition parameters for oriented polycrystalline $\mathrm{CeO}_{2}$ include current density lower than $-0.06 \mathrm{~mA} / \mathrm{cm}^{2}$ with galvanostatic deposition mode and deposition temperatures higher than $50^{\circ} \mathrm{C}$. $\mathrm{X}$-ray diffraction showed the deposited films crystallite size in the nanometer size range, which was further confirmed with Raman. Scanning electron microscopy shows a smooth surface and cracked appearance of the deposits. Sintering and corrosion experiments were conducted on the deposited films to further illustrate the properties and the possible applications of these thin films. Detailed investigations about optical, electrical, and catalytic properties of cerium oxide films may expand its application perspective. Also, anodic electrodeposition is a relatively novel synthesis technique for ceramic oxides and worthwhile to extend to other materials. Praseodymium and neodymium oxide depositions with this method are underway in our research group.

\section{References}

[1] N. Özer, J. P. Cronin, and S. Akyuz, "Electrochromic performance of sol-gel deposited $\mathrm{CeO}_{2}$ films," in Proceedings of the Society of Photo-Optical Instrumentation, vol. 3788, pp. 103-110, July 1999.

[2] A. Wang, J. A. Belot, T. J. Marks et al., "Buffers for high temperature superconductor coatings. Low temperature growth of $\mathrm{CeO}_{2}$ films by metal-organic chemical vapor deposition and their implementation as buffers," Physica C, vol. 320, no. 3, pp. 154-160, 1999.

[3] A. Trovarelli, "Catalytic properties of ceria and $\mathrm{CeO}_{2}$ containing materials," Catalysis Reviews, vol. 38, no. 4, pp. 439-520, 1996.

[4] J. Gerblinger, W. Lohwasser, U. Lampe, and H. Meixner, "High temperature oxygen sensor based on sputtered cerium oxide," Sensors and Actuators B, vol. 26, no. 1-3, pp. 93-96, 1995.

[5] E. S. Putna, J. Stubenrauch, J. M. Vohs, and R. J. Gorte, "Ceriabased anodes for the direct oxidation of methane in solid oxide fuel cells," Langmuir, vol. 11, no. 12, pp. 4832-4837, 1995.
[6] A. L. Rudd, C. B. Breslin, and F. Mansfeld, "The corrosion protection afforded by rare earth conversion coatings applied to magnesium," Corrosion Science, vol. 42, no. 2, pp. 275-288, 2000.

[7] X. D. Wu, R. C. Dye, R. E. Muenchausen et al., "Epitaxial $\mathrm{CeO}_{2}$ films as buffer layers for high-temperature superconducting thin films," Applied Physics Letters, vol. 58, no. 19, pp. 2165-2167, 1991.

[8] T. Inoue, Y. Yamamoto, S. Koyama, S. Suzuki, and Y. Ueda, "Epitaxial growth of $\mathrm{CeO}_{2}$ layers on silicon," Applied Physics Letters, vol. 56, no. 14, pp. 1332-1333, 1990.

[9] M. W. Denhoff and J. P. McCaffrey, "Epitaxial $\mathrm{Y}_{1} \mathrm{Ba}_{2} \mathrm{Cu}_{3} \mathrm{O}_{7}$ thin films on $\mathrm{CeO}_{2}$ buffer layers on sapphire substrates," Journal of Applied Physics, vol. 70, no. 7, pp. 3986-3988, 1991.

[10] D. R. Arnott, B. R. W. Hinton, and N. E. Ryan, "Cationic-filmforming inhibitors for the protection of the AA 7075 aluminum alloy against corrosion in aqueous chloride solution," Corrosion, vol. 45, no. 1, pp. 12-18, 1989.

[11] A. C. Crossland, G. E. Thompson, P. Skeldon et al., "Anodic oxidation of Al-Ce alloys and inhibitive behaviour of cerium species," Corrosion Science, vol. 40, no. 6, pp. 871-885, 1998.

[12] M. A. Arenas, A. Conde, and J. J. de Damborenea, "Cerium: a suitable green corrosion inhibitor for tinplate," Corrosion Science, vol. 44, no. 3, pp. 511-520, 2002.

[13] J. A. Switzer, "Electrochemical synthesis of ceramic films and powders," American Ceramic Society Bulletin, vol. 66, no. 10, pp. $1521-1524,1987$.

[14] I. Zhitomirsky and A. Petric, "Electrolytic and electrophoretic deposition of $\mathrm{CeO}_{2}$ films," Materials Letters, vol. 40, no. 6, pp. 263-268, 1999.

[15] F.-B. Li and G. E. Thompson, "In situ atomic force microscopy studies of the deposition of cerium oxide films on regularly corrugated surfaces," Journal of the Electrochemical Society, vol. 146, no. 5, pp. 1809-1815, 1999.

[16] Y. Zhou and J. A. Switzer, "Growth of cerium(IV) oxide films by the electrochemical generation of base method," Journal of Alloys and Compounds, vol. 237, no. 1-2, pp. 1-5, 1996.

[17] A. J. Aldykiewicz Jr., A. J. Davenport, and H. S. Isaacs, "Studies of the formation of cerium-rich protective films using X-ray absorption near-edge spectroscopy and rotating disk electrode methods," Journal of the Electrochemical Society, vol. 143, no. 1, pp. 147-154, 1996.

[18] A. Q. Wang and T. D. Golden, "Anodic deposition of cerium oxide: I. Formation of crystalline thin films," Journal of the Electrochemical Society, vol. 150, no. 9, pp. C616-C620, 2003.

[19] T. D. Golden and A. Q. Wang, "Anodic deposition of cerium oxide thin films: II. Mechanism studies," Journal of the Electrochemical Society, vol. 150, no. 9, pp. C621-C624, 2003.

[20] A. Q. Wang, P. Punchaipetch, R. M. Wallace, and T. D. Golden, "X-ray photoelectron spectroscopy study of electrodeposited nanostructured $\mathrm{CeO}_{2}$ films," Journal of Vacuum Science and Technology B, vol. 21, no. 3, pp. 1169-1175, 2003.

[21] E. A. Kulp, S. J. Limmer, E. W. Bohannan, and J. A. Switzer, "Electrodeposition of nanometer-thick ceria films by oxidation of cerium(III)-acetate," Solid State Ionics, vol. 178, no. 11-12, pp. 749-757, 2007.

[22] M. Balasubramanian, C. A. Melendres, and A. N. Mansour, "X-ray absorption study of the local structure of cerium in electrochemically deposited thin films," Thin Solid Films, vol. 347, no. 1-2, pp. 178-183, 1999. 
[23] E. Stoyanova and D. Stoychev, "Corrosion behavior of stainless steels modified by cerium oxides layers," in Corrosion Resistance, H. Shih, Ed., pp. 239-270, InTech Press, 2012.

[24] S. Hastuty, A. Nishikata, and T. Tsuru, "Pitting corrosion of Type 430 stainless steel under chloride solution droplet," Corrosion Science, vol. 52, no. 6, pp. 2035-2043, 2010.

[25] M. Finšgar, S. Fassbender, S. Hirth, and I. Milošev, "Electrochemical and XPS study of polyethyleneimines of different molecular sizes as corrosion inhibitors for AISI 430 stainless steel in near-neutral chloride media," Materials Chemistry and Physics, vol. 116, no. 1, pp. 198-206, 2009.

[26] F. A. Cotton, G. Wilkinson, C. A. Murillo, and M. Bochmann, Advanced Inorganic Chemistry: A Comprehensive Text, John Wiley \& Sons, New York, NY, USA, 4th edition, 1980.

[27] N. W. Alcock, V. M. Tracy, and T. C. Waddington, "Acetates and acetate-complexes. Part 1. Preparation of acetato-complexes and conductimetric studies in the acetic anhydride solvent system," Journal of the Chemical Society, Dalton Transactions, no. 21, pp. 2238-2242, 1976.

[28] N. W. Alcock, V. M. Tracy, and T. C. Waddington, "Acetates and acetato-complexes. Part 2. Spectroscopic studies," Journal of the Chemical Society, Dalton Transactions, no. 21, pp. 2243-2246, 1976.

[29] N. W. Alcock and V. L. Tracy, "Acetates and acetato-complexes. Part 3. The crystal and molecular structure of tetramethylammonium penta-acetatostannate(IV)," Journal of the Chemical Society, Dalton Transactions, no. 21, pp. 2246-2249, 1976.

[30] Y. Mathey, D. R. Greig, and D. F. Shriver, "Variable-temperature Raman and infrared spectra of the copper acetate dimer $\mathrm{Cu}_{2}\left(\mathrm{O}_{2} \mathrm{CCH}_{3}\right)_{4}\left(\mathrm{H}_{2} \mathrm{O}\right)_{2}$ and its derivatives," Inorganic Chemistry, vol. 21, no. 9, pp. 3409-3413, 1982.

[31] J. Stubenrauch and J. M. Vohs, "Interaction of CO with Rh supported on stoichiometric and reduced $\mathrm{CeO}_{2}(111)$ and $\mathrm{CeO}_{2}(100)$ surfaces," Journal of Catalysis, vol. 159, no. 1, pp. 50-57, 1996.

[32] F. Vratny, C. N. R. Rao, and M. Dilling, "Infrared spectra of metal acetates," Analytical Chemistry, vol. 33, no. 10, p. 1455, 1961.

[33] M. E. Azenha, H. D. Burrows, S. M. Fonseca et al., "Luminescence from cerium(III) acetate complexes in aqueous solution: considerations on the nature of carboxylate binding to trivalent lanthanides," New Journal of Chemistry, vol. 32, no. 9, pp. 15311535, 2008.

[34] S. Wang, W. Wang, J. Zuo, and Y. Qian, "Study of the Raman spectrum of $\mathrm{CeO}_{2}$ nanometer thin films," Materials Chemistry and Physics, vol. 68, no. 1-3, pp. 246-248, 2001.

[35] W. H. Weber, K. C. Hass, and J. R. McBride, "Raman study of $\mathrm{CeO}_{2}$ : second-order scattering, lattice dynamics, and particlesize effects", Physical Review B, vol. 48, no. 1, pp. 178-185, 1993.

[36] M. S. P. Francisco, V. R. Mastelaro, P. A. P. Nascente, and A. O. J. Florentino, "Activity and characterization by XPS, HR-TEM, Raman spectroscopy, and bet surface area of $\mathrm{CuO} / \mathrm{CeO}_{2}-\mathrm{TiO}_{2}$ catalysts," Journal of Physical Chemistry B, vol. 105, no. 43, pp. 10515-10522, 2001.

[37] J. Twu, C. J. Chuang, K. I. Chang, C. H. Yang, and K. H. Chen, "Raman spectroscopic studies on the sulfation of cerium oxide," Applied Catalysis B, vol. 12, no. 4, pp. 309-324, 1997.

[38] P. Papaiacovou, R. J. Hussey, D. F. Mitchell, and M. J. Graham, "The effect of $\mathrm{CeO}_{2}$ coatings on the oxidation behaviour of $\mathrm{Fe}$ $20 \mathrm{Cr}$ alloys in $\mathrm{O}_{2}$ at $1173 \mathrm{~K}$," Corrosion Science, vol. 30, no. 4-5, pp. 451-460, 1990.
[39] F. Czerwinski and J. A. Szpunar, "Optimizing properties of $\mathrm{CeO}_{2}$ sol-gel coatings for protection of metallic substrates against high temperature oxidation," Thin Solid Films, vol. 289, no. 1-2, pp. 213-219, 1996.

[40] H. P. Klug and L. E. Alexander, X-Ray Diffraction Procedures For Polycrystalline and Amorphous Materials, John Wiley \& Sons, New York, NY, USA, 2nd edition, 1974.

[41] N. Shaigan, W. Qu, D. G. Ivey, and W. Chen, "A review of recent progress in coatings, surface modifications and alloy developments for solid oxide fuel cell ferritic stainless steel interconnects," Journal of Power Sources, vol. 195, no. 6, pp. 1529$1542,2010$.

[42] F. Martín, C. García, P. de Tiedra, Y. Blanco, and M. L. Aparicio, "Sensitization of powder metallurgy type 430L stainless steel sintered in nitrogen-hydrogen atmosphere," Corrosion, vol. 64, no. 1, pp. 70-82, 2008.

[43] I. Zhitomirsky and A. Petric, "The electrodeposition of ceramic and organoceramic films for fuel cells," Journal of Organic Materials, vol. 53, no. 9, pp. 48-50, 2001.

[44] R. M. German, Sintering Theory and Practice, John Wiley \&. Sons, 1996. 

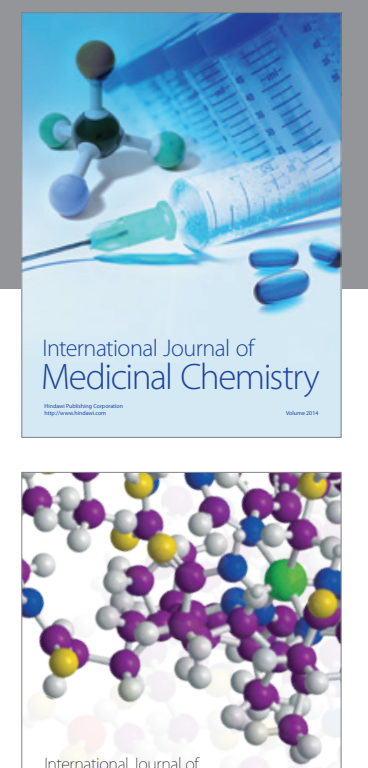

\section{Carbohydrate} Chemistry

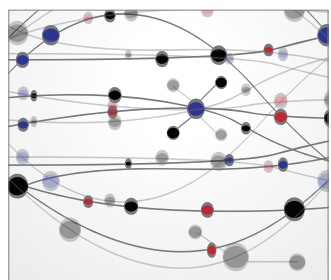

The Scientific World Journal
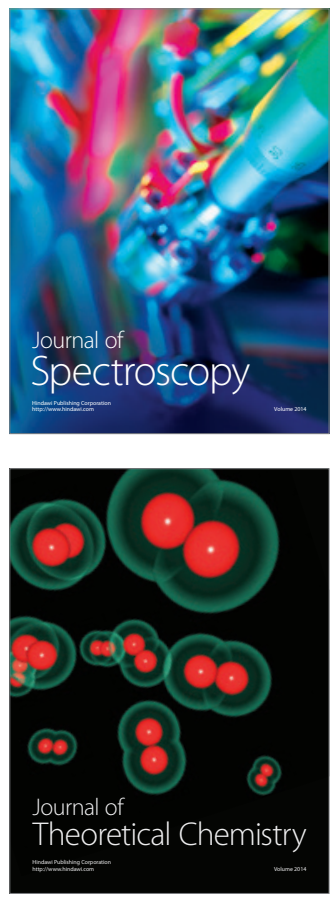
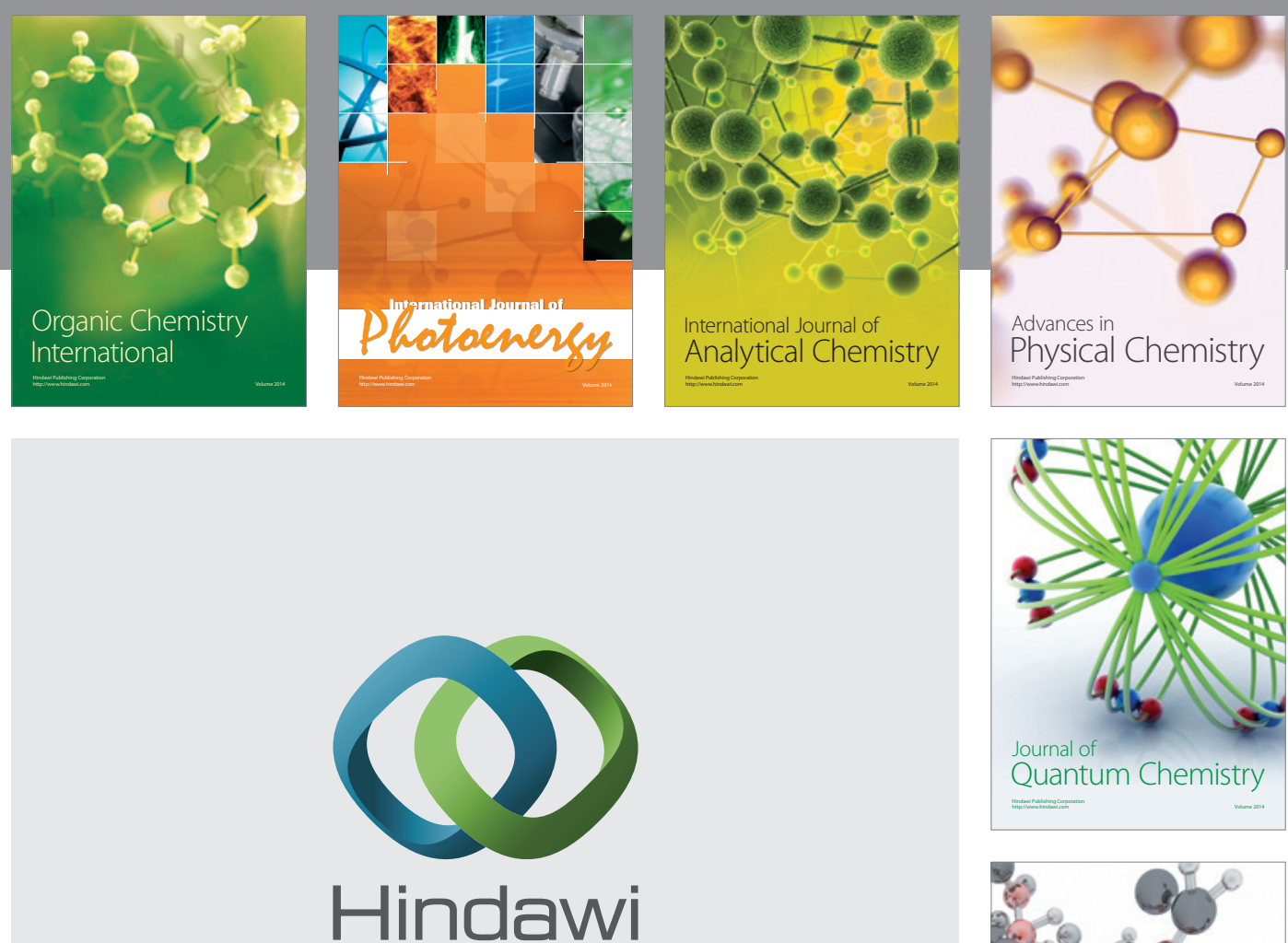

Submit your manuscripts at

http://www.hindawi.com

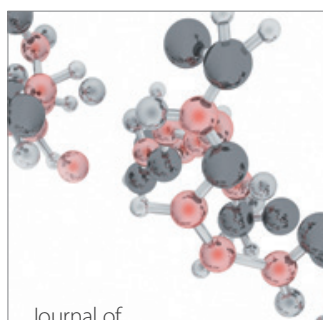

Analytical Methods

in Chemistry

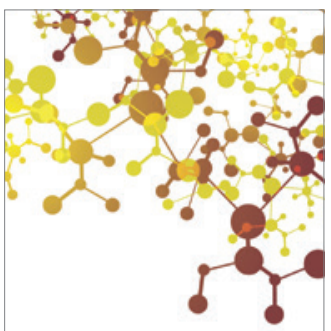

Journal of

Applied Chemistry

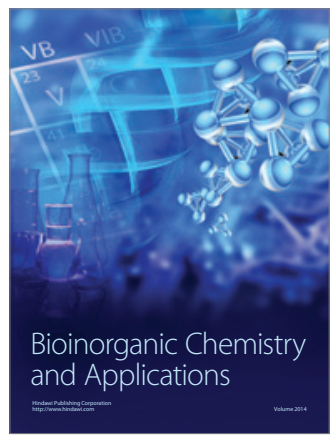

Inorganic Chemistry
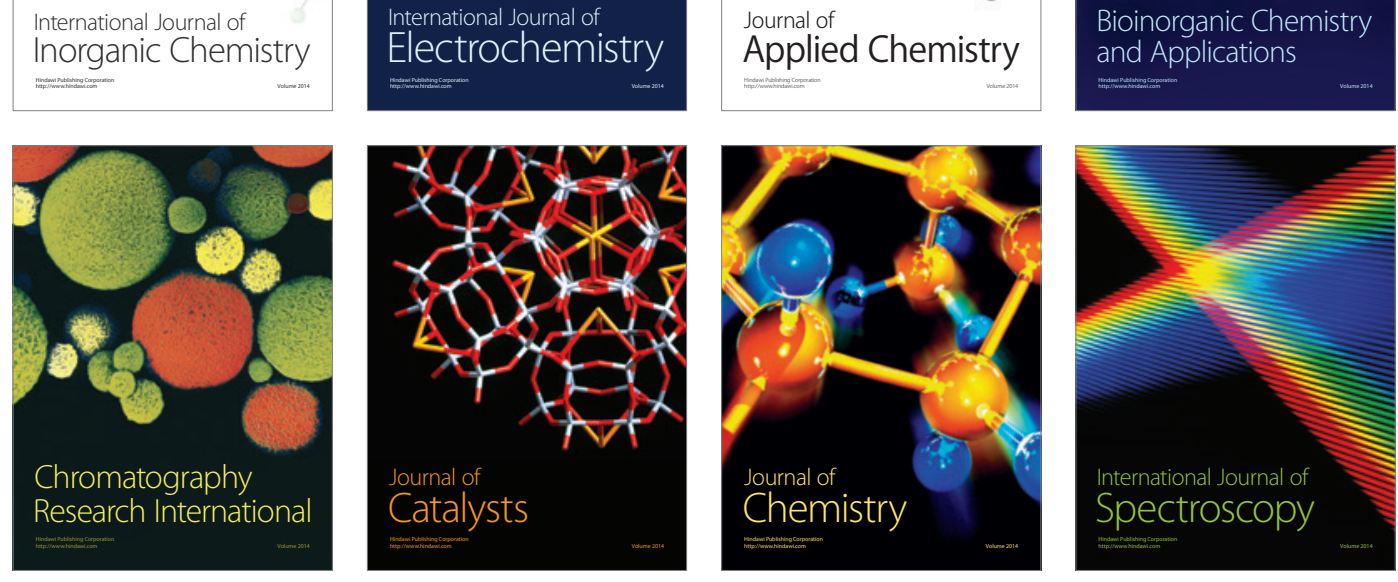